\title{
Comparison of remote sensing extraction methods for glacier firn line- considering Urumqi Glacier No.1 as the experimental area
}

\author{
YANJUN ZHAO ${ }^{1}$, JUN ZHAO ${ }^{1}$, XIAOYING YUE²and YANQIANG WANG ${ }^{1}$ \\ ${ }^{1}$ College of Geography and Environmental Science, Northwest Normal University, Lanzhou, China \\ ${ }^{2}$ State Key Laboratory of Cryospheric Sciences, Northwest Institute of Eco-Environment and Resources/Tien Shan Glaciological Station, \\ Chinese Academy of Sciences, Lanzhou, China
}

\begin{abstract}
In mid-latitude glaciers, the altitude of the snowline at the end of the ablating season can be used to indicate the equilibrium line, which can be used as an approximation for it. In this paper, Urumqi Glacier No.1 was selected as the experimental area while Landsat TM/ETM+/OLI images were used to analyze and compare the accuracy as well as applicability of the visual interpretation, Normalized Difference Snow Index, single-band threshold and albedo remote sensing inversion methods for the extraction of the firn lines. The results show that the visual interpretation and the albedo remote sensing inversion methods have strong adaptability, alonger with the high accuracy of the extracted firn line while it is followed by the Normalized Difference Snow Index and the single-band threshold methods. In the year with extremely negative mass balance, the altitude deviation of the firn line extracted by different methods is increased. Except for the years with extremely negative mass balance, the altitude of the firn line at the end of the ablating season has a good indication for the altitude of the balance line.
\end{abstract}

\section{Introduction}

Snow cover and glaciers are important components of the geographical environment. For instance, the glacier cover area change affects the absorption of solar radiation and has a significant influence on different scales of climate change[1]. Meanwhile, glaciers also record variations about the surrounding information and environment as well as the climate so that they are used as indicators of global climate change[2-3].

The mass balance line is the boundary between the glacial accumulation and the ablation zones. Its altitude refers to the point where the annual mass income and expenditure of the glacier are equal, It also indicates the zero-balance line between the year-round snow cover (accumulation zone) and the snow-free zone (ablation zone) in summer. LaChapelle et al. [4] proposed that the snowline altitude at the end of the ablating season (namely, the firn line) could be used to indicate the altitude of the mass balance line in terms of mid-latitude glaciers. For this reason, the snowline altitude at the end of the ablating season can be used as an approximation of the glacier balance line altitude to estimate the mass balance and climate reconstruction [5].

The mass balance line is usually measured directly by the flower-pole/snow-pit method and can only be carried out on very limited glaciers. On the other hand, the improvements in remote sensing technology have provide opportunities for extraction firn line by remote sensing data. Currently, there are four common methods in obtaining the firn line by using remote sensing images. In the first one, it is extracted from remote sensing images direct visual interpretation with topographic maps[6]. The second one depends on the snow cover index methods. For instance, in the Normalized Difference Snow Index (NDSI). With the threshold value of $0.57 \leq \mathrm{NDSI} \leq 0.72$ is set to identify the range of snow cover[7]. The third one is the single-band threshold method where the gray threshold value of 90 160 in the Thematic Mapper(TM)4 band is set to extract the snow cover range [8]. The fourth one is the albedo inversion algorithm[9-10]. Each extraction method provides varying results for the same glacier. However, there are few comparative studies on these extraction methods as well as the evaluation of the adaptability .

Urumqi Glacier No.1 is located at the source of the Urumqi River, which lies on the north slope of Kalawocheng Mountain and in the middle part of the Tien shan Mountains $\left(86^{\circ} 48^{\prime} \mathrm{E}-43^{\circ} 07^{\prime} \mathrm{N}\right)$. With a varying altitude between $3752 \sim 4445 \mathrm{~m}$, it is composed of east and west branches with a glacier area of $1.59 \mathrm{~km}^{2}$ (2012). Its east branch of $1.02 \mathrm{~km}^{2}$, and very close to the national average glacier area as published in the second glacier cataloging (Fig.1). The mass balance of the glacier is consistent with the world standard curve and has a good representation. It has long-term observational and research data, so that Urumqi Glacier No.1 is selected as the experimental area in this study. LandsatTM/ETM+/OLI images were used to analyze and compare the performance as well as the accuracy of the visual interpretation, Normalized Difference Snow Index, single-band 
threshold and albedo remote sensing inversion methods to extract glacier firn line. They are expected to provide a reference for selecting the altitude of the glacier firn line by using remote sensing data and estimating the mass balance in the Tien shan region by using the firn line at the end of the ablating season.

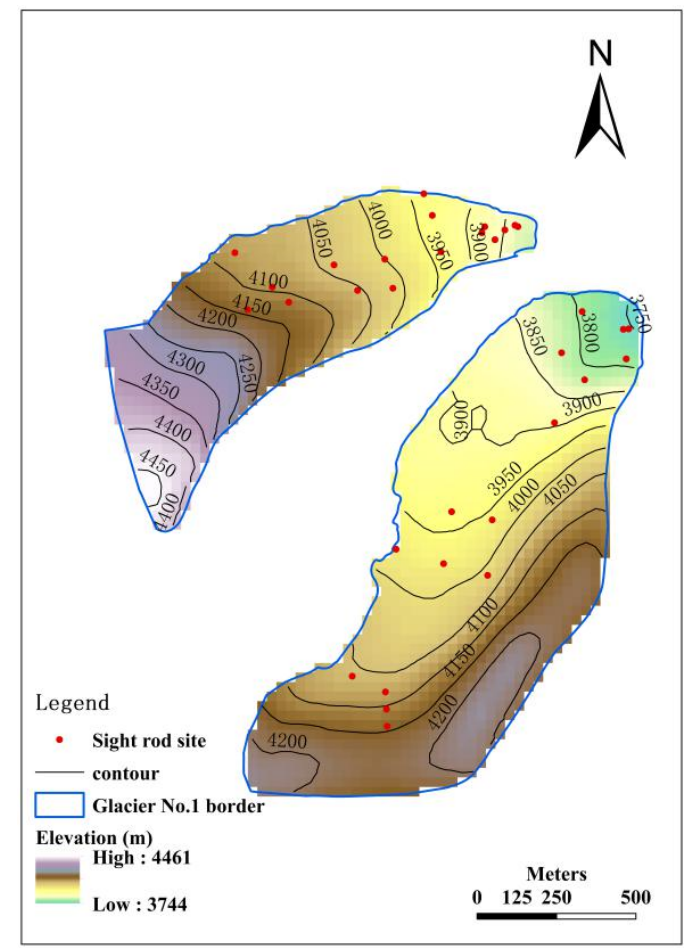

Fig1. The study area

\section{Study data and method}

\subsection{Study data}

In this paper, TM/ETM+/OLI images from the end of the ablating season of Urumqi Glacier No.1 from 2002 to 2015 are used as the main data source. The dataset is obtained from the US Geological Survey (https://earthexplorer.usgs.gov/). The spatial resolution of DEM data used is $30 \mathrm{~m}$ while the vertical precision is about $20 \mathrm{~m}$. It is derived from the geospatial data cloud(http://www.gscloud.cn/home), which has good spatial consistency with TM/ETM+/OLI images. The onsite altitude of the mass balance line was measured by the observation staff of Tien shan Glacier Station through the sight rod/snow-pit method.

The remote sensing images are selected by considering the period as much close as possible to the end of the ablating season. Meanwhile, cloud cover and new snowfall events were avoided while artificial screening was carried out in combination with meteorological data. Then, the image data are preprocessed by radiometric calibration, atmospheric correction, terrain correction and space registration. WGS 1984 coordinate system and transverse Mercator projection were used for the datasets.

\subsection{Study method}

\subsubsection{Firn line extraction method}

As the first step, the selected method is used to extract the snow range to obtain the position of the firn line. Then, the pixel elevations of the firn line corresponding to DEM are considered to determine the average elevation of firn line.

(1) Visual interpretation method

The ENVI5.3 software is used to combine the bands of the selected images. The bands of 3,2 and 1 , are considered for TM/ETM+ while 4, 3, and 2, are used in OLI. RGB images are obtained for both datasets to obtain a synthesized image close to natural color. The remote sensing images indicated significantly different spectral values for the substances at the end of the ablating season. For instance, the additional ice was translucent or milky white while the glacier ice was completely transparent. The snow line is easy to be identified visually when combined with field investigation.

(2) Normalized Difference Snow Index (NDSI).

The band operation is carried out on the image by using the combination of green light and short-wave infrared band, and the snow cover area to extract from the processed image. The NDSI is obtained by:

$$
N D S I=\frac{\text { Green }-S W I R 1}{\text { Green }+ \text { SWIR } 1}
$$

(3) Single-band threshold method

Due to the large difference in reflectance between ice and snow in the near-infrared band (760 960nm), the $\mathrm{TM} / \mathrm{ETM}+4$ and OLI5 band were considered. The gray threshold 90 160 was set as to extract snow.

(4) Albedo remote sensing inversion method

For the preprocessed images, the Bidirectional Reflectance Distribution Function(BRDF) and Knap models were used for anisotropy correction and narrowwide band conversion respectively to obtain the spatial distribution of glacier albedo. On the registered DEM, contour lines are extracted at $50 \mathrm{~m}$ intervals and superimposed with the spatial distribution data of glacier albedo to calculate the albedo on the central line of the glacier. According to the results, the threshold is divided and the glacier surface is divided to determine the altitude of the firn line.

\subsubsection{Accuracy comparison and evaluation method}

\section{(1) Correlation coefficient (CC)}

The correlation coefficient is used to reflect the relationship between the altitude of the extracted firn line and the altitude of the measured balance line where the formulation is defined as:

$$
C C=\frac{\sum_{i=1}^{n}\left(x_{i}-\bar{x}\right)\left(y_{i}-\bar{y}\right)}{\sqrt{\sum_{i=1}^{n}\left(x_{i}-\bar{x}\right) \sum_{i=1}^{n}\left(y_{i}-\bar{y}\right)}}
$$

(2) Determination coefficient $\left(\mathrm{R}^{2}\right)$

The determination coefficient is also known as the goodness of fit. It helps to reflect the interpretation level of the extracted firn line altitude to the measured equilibrium line altitude as the formulation is defined as 
follows:

$$
R^{2}=\frac{\left(\sum_{i=1}^{n} x_{i} y_{i}\right)^{2}}{\left(\sum_{i=1}^{n} x_{i}^{2}\right)\left(\sum_{i=1}^{n} y_{i}^{2}\right)}
$$

(3) Absolute error (E) and relative error (RE)

The absolute and relative errors between the extracted firn line altitude and the measured equilibrium line altitude are used to reflect the differences between the two and are obtained by:

$$
\begin{array}{r}
E=\mathrm{x}_{\mathrm{i}}-\mathrm{y}_{i} \\
R E=\frac{E}{\mathrm{x}_{i}} * 100 \%
\end{array}
$$

(4) Mean deviation (D)and standard deviation (S)

The mean and standard deviations are used to reflect the mutual proximity between the extracted firn line and the measured equilibrium line altitude as the calculation formulations are defined as:

$$
\begin{array}{r}
D=\frac{\sum_{i=1}^{n}\left|\mathrm{z}_{i}-\overline{\mathrm{z}}\right|}{n} \\
S=\sqrt{\frac{\sum\left(z_{i}-\overline{\mathrm{z}}\right)^{2}}{n-1}}
\end{array}
$$

For the formulas (2)-(5), $\mathrm{x}_{\mathrm{i}}$ is the measured equilibrium line altitude; $y_{i}$ is the altitude of firn line extracted by remote sensing; $\bar{x}$ is the measured average equilibrium line altitude, and $\bar{y}$ is the average altitude of firn line extracted by remote sensing; for the formulas (6)-(7), $\mathrm{z}_{\mathrm{i}}$ is the measured equilibrium line altitude and the altitude of firn line extracted by remote sensing; $\bar{z}$ is the average measured equilibrium line altitude and the altitude of firn line extracted by remote sensing.

\section{Results from analysis and discussion}

\subsection{The accuracy evaluation of the firn line extracted by four methods}

The method of visual interpretation, Normalized Difference Snow Index, single-band threshold and albedo remote sensing inversion,were used to extract the firn line altitude, for the east and west branches of Urumqi Glacier No.1, considering the period of 2002 - 2015. Fig.2 shows a sample of the extracted firn lines in 2015.

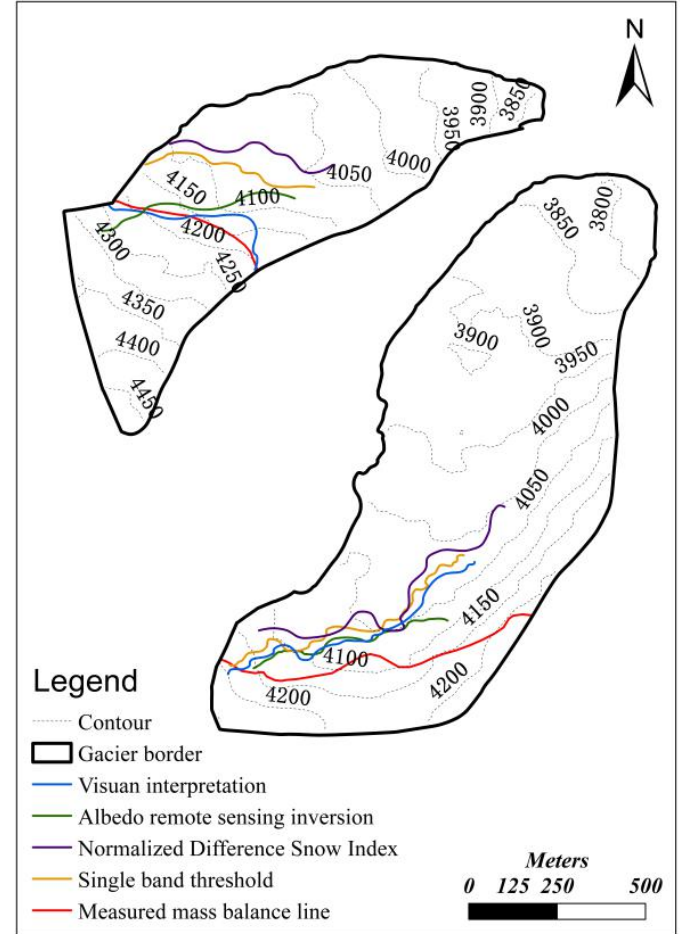

Fig2. Firn line extracted by using four methods (2015-8-26)

The altitude of the measured mass balance line is considered as the "truth value"during the analysis. The results obtained from formulas $(2) \sim(7)$ are provided in Table 1, fig.3 and fig.4.

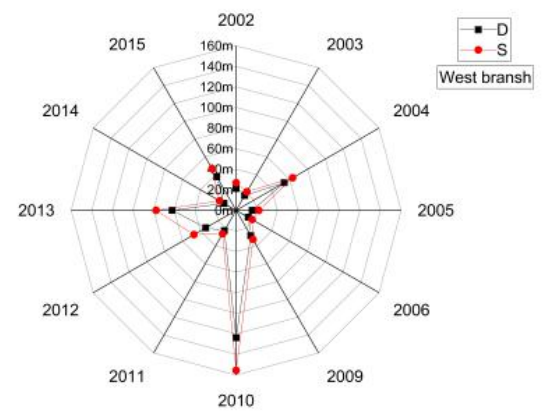

Fig3. D and RD in different years(East bransh)

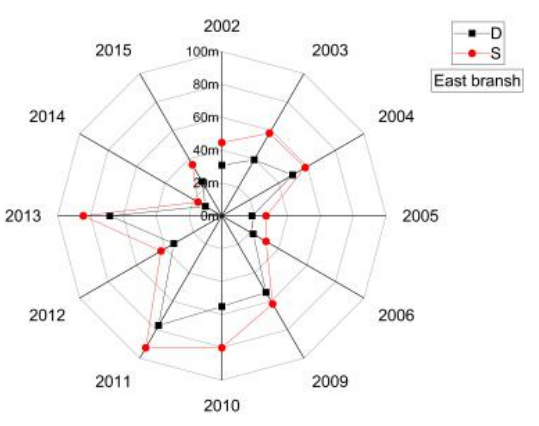

Fig4. D and RD in different years(West bransh)

The results in fig.3, fig. 4 and table. 1 showed that, except for the single-band threshold method, the variation trend of the firn line altitude obtained by the other three methods in different years is highly consistent with that of the measured mass balance line altitude. The order of consistency relationship from stronger to weaker is 
obtained as visual interpretation, albedo remote sensing inversion, Normalized Difference Snow Index, and single- band threshold methods. It is shown that the visual

Table1. Comparation of CC, $\mathrm{R}^{2}, \mathrm{E}$ and RE concerning four methods

\begin{tabular}{|c|c|c|c|c|c|c|c|c|c|}
\hline & & \multicolumn{2}{|c|}{$\begin{array}{c}\text { Visual } \\
\text { interpretation } \\
\text { method } \\
\end{array}$} & \multicolumn{2}{|c|}{$\begin{array}{c}\text { Normalized } \\
\text { Difference Snow } \\
\text { Index } \\
\end{array}$} & \multicolumn{2}{|c|}{$\begin{array}{l}\text { Single-band } \\
\text { threshold method }\end{array}$} & \multicolumn{2}{|c|}{$\begin{array}{c}\text { Albedo remote } \\
\text { sensing inversion } \\
\text { method }\end{array}$} \\
\hline & & $\begin{array}{c}\text { East } \\
\text { branch }\end{array}$ & $\begin{array}{c}\text { West } \\
\text { branch }\end{array}$ & $\begin{array}{c}\text { East } \\
\text { branch }\end{array}$ & $\begin{array}{c}\text { West } \\
\text { branch }\end{array}$ & $\begin{array}{c}\text { East } \\
\text { branch }\end{array}$ & $\begin{array}{c}\text { West } \\
\text { branch }\end{array}$ & $\begin{array}{c}\text { East } \\
\text { branch }\end{array}$ & $\begin{array}{c}\text { West } \\
\text { branch }\end{array}$ \\
\hline & $\mathrm{CC}$ & 0.91 & 0.98 & 0.78 & 0.84 & 0.62 & 0.35 & 0.97 & 0.95 \\
\hline & $\mathrm{R}^{2}$ & 0.81 & 0.96 & 0.57 & 0.68 & 0.33 & 0.12 & 0.94 & 0.89 \\
\hline \multirow{4}{*}{$\mathrm{E}$} & maximum & 64 & 40 & 183 & 126 & 179 & 166 & 105 & 65 \\
\hline & minimum & 7 & -13 & 10 & 7 & -22 & 9 & -9 & -2 \\
\hline & mean & 24.25 & 22.75 & 76.33 & 59.92 & 73.75 & 55.5 & 35.6 & 26.08 \\
\hline & variance & 422.35 & 121.35 & 2853.56 & 1534.57 & 3046.35 & 1968.25 & 917.72 & 401.41 \\
\hline \multirow{4}{*}{ RE } & maximum & 1.57 & 1.04 & 4.52 & 3.06 & 4.41 & 4.08 & 2.55 & 1.54 \\
\hline & minimum & 0.17 & -0.32 & 0.25 & 0.17 & -0.54 & 0.22 & -0.22 & -0.05 \\
\hline & mean & 0.59 & 0.55 & 1.91 & 1.47 & 1.84 & 1.36 & 0.87 & 0.63 \\
\hline & variance & 0.26 & 0.07 & 1.77 & 0.92 & 1.92 & 1.16 & 0.54 & 0.23 \\
\hline
\end{tabular}

interpretation and albedo remote sensing inversion methdhave high interpretability while the single-band threshold method has the lowest. In terms of absolute and relative error, the difference between the altitude of the firn line extracted by different methods and the measured mass balance line altitude is obtained in the order from smaller to larger as visuainter pretation, albedo remote sensing inversion, Normalized Difference Snow Index and single-band threshold methods. The altitude of the firn line obtained by the four methods is lower than the altitude of measured mass balance line altitude in most years. However thereare few cases, like in 2009 and 2014, it was higher than the measured mass balance line altitude. On the other hand, the relative error obtained by the four methods in extracting the firn line was small. The order of the difference from smaller to larger is determined as visual interpretation, albedo remote sensing inversion, Normalized Difference Snow Index and single-band threshold methods. The absolute error and relative error showed similar results for the east and the west branch.

\subsection{Characteristics of four extraction methods of firn line}

(1) Characteristics of extraction of firn line by visual interpretation method

The method is simple, convenient, and easy to operate. The elevation accuracy of the extracted firn line is good. However, the workload is large and the efficiency is low. In terms of the altitude of firn lines extracted in this study, the east branch showed significant deviation in the years of 2002, 2010, 2011, and 2015, while results are observed in 2010 and 2015, in the west btanch. It indicates that the adaptability of this method in the west branch was higher than that in the east branch. When the visual interpretation method is used to extract the altitude of firn line, image and glacier characteristics should be taken into comprehensive consideration as well as non-remote sensing data.For instance large-scale topographic maps should be combined for comprehensive analysis and reasoning as it could effectively improve the accuracy of extraction.

(2) Characteristics of extraction of firn line by NDSI

The method is simple in operation with high efficiency while the extraction precision is significantly lower than that of the visual interpretation method. The NDSI threshold is the most important factor affecting the result accuracy. Based on the previous results [7], through repeated tests and combined with the actual situation of Urumqi Glacier No.1 and visual interpretation results, it is believed that the NDSI threshold of $0.75 \sim 0.96$ is suitable for area.

(3) Characteristics of extraction of firn line by the single-band method

This method is relatively simple and easy to implement with high efficiency. The elevation accuracy of the extracted firn line is low while the extraction accuracy mainly depends on the setting of the threshold value. In this study, the gray threshold of the near-infrared band was set as 90-160. The gray map was converted into a binaryvalue map of snow distribution to extract firn lines by considering the previous studies. The resulting accuracy is the lowest among the four methods. There is no further adjustment, comparison, and analysis than its threshold setting.

(4) Albedo remote sensing inversion method

This method is relatively complex with large amounts of calculation and has certain difficulty in the data processing. The extracted firn line elevation is consistent with the measured mass balance line elevation as well as the extracted result is highly accurate. The key step of this method is to partition the threshold value according to the distribution attribute of glacier surface albedo .

\subsection{Cause analysis of the firn line extraction error}

The analysis of the extracted firn line altitude showed that the elevation values of the firn line obtained by the four 
methods are lower than the measured mass balance line altitude in most years. For instance, larger absolute errors are obtained in 2010 and 2011.Indeed, the relationship between the firn line and the mass balance line is not consistent and differs from time to time.

First of all, at the end of the mass balance ablating year, the glaciers are melting so strongly that all the previous year's snow on the surface is gone on the glacier surface in the year of extremely negative mass balance for continental glaciers. On the other hand, firn appears on the surface of the glacier while the additional ice band and firn area begin to melt. For this reason, the altitude of the equilibrium line appears to be higher than the firn line, even higher than the highest point of the glacier. There are some differences in the elevation of the firn line extracted by four methods, for the years when the extreme negative value of the mass balance appears to increase the absolute error value (Fig.5).
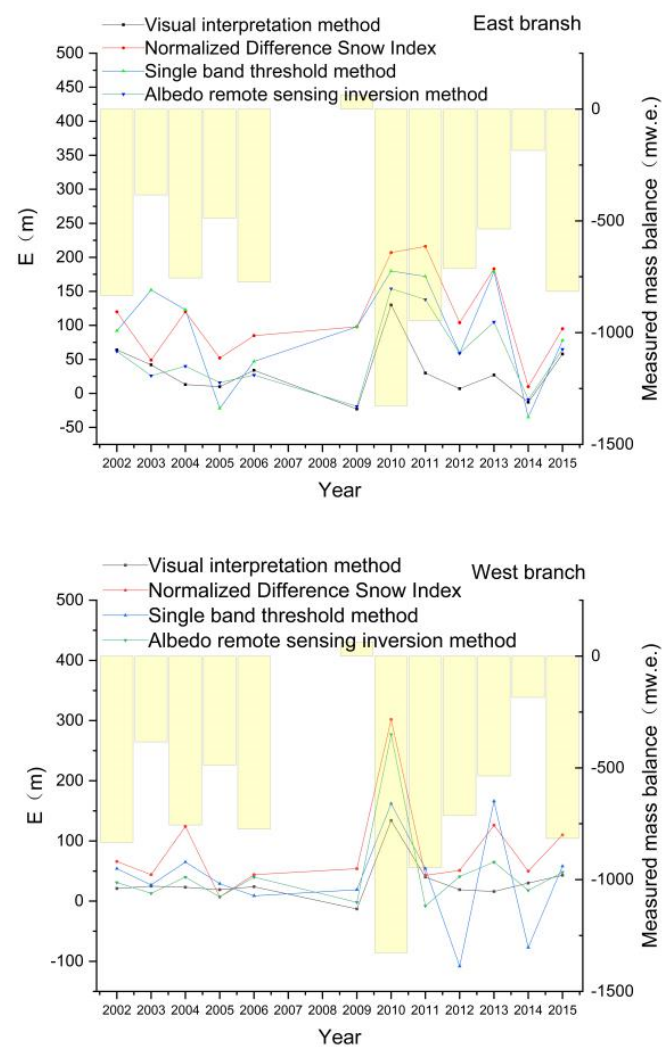

Fig5. Relationship between absolute error and measured mass balance within the same period

Secondly, it is not possible to collect the idea image data exactly due to the mismatch of the operating cycle of Landsat and the available image acquisition time. Therefore, in most cases, the inverted firn line is not the theoretical maximum firn line altitude in the year of glacier mass balance. For this reason, it is expected to contribute some amount of error between the firn line and the measured mass balance line.

In addition, extraction of the snow line using remote sensing data is also affected by geometric registration and image resolution as well as new snowfall events, terrain blockage, glacier surface slope and wind-driven snow events.

\section{Conclusion}

Based on remote sensing image TM/ETM+/OLI and DEM data, for the experimental area of Urumqi Glacier No.1, linear fitting and accuracy evaluation were carried out for the firn line and the measured mass balance altitude determination using visual interpretation, Normalized Difference Snow Index, single-band threshold and albedo remote sensing inversion methods. The results show that the visual interpretation and the albedo remote sensing inversion methods have strong adaptability with the high interpretation accuracy as followed by the Normalized Difference Snow Index and the single-band threshold methods. The occurrence of the extreme negative value of mass balance intensified the difference in the altitude of the firn line extracted by four different methods. Except for the years with extremely negative mass balance, the altitude of the firn line at the end of the ablating season has a good indication for the altitude of the equilibrium line.

\section{references}

1. S.W.Wang,[J].Geographic research, 03, 73-86(1983)

2. Haeberli W, Hoelzle M, Paul F,et al.the European Alps[J]. Annals of Glaciology, 46(1),150-160 (2007)

3. Rye C,Arnold N, Willis I,et al[J].Journal of Geophysical Research Atmospheres,115(F2), 141150(2010)

4. Rabatel A,Dedieu J,Vincent C. [J]. Journal Glaciology, 51(175),539-546(2005)

5. W. Y,H. J,Guo Z,et al. [J].Journal of Glaciology, 60(224): 1093-1100(2014)

6. Q.B.[Zhang,S.C.Kang,G.S.Zhang,ScientiaGeographi ca Sinica,36(12):1937-1944,(2016)

7. J.Wang, $[\mathrm{J}]$. Remote Sensing Technology and Application,12 (4) ,29-36(1999)

8. A.A.Chen,W.Wu . [J] .Journal of Glaciology and Geocryology,36( 5) ,1069 - 1078(2014)

9. F.Xiao,Y.Dun,F.LinG,et al.[J].Journal of Remote Sensing, 14 (1) ,55-67(2010)

10. X.Y.Yue. [D]. Northwest Normal University,2018 